\section{Frontier of Medicinal Science}

\section{November-2 December 2011 Tokyo, Japan}

\section{The 8th AFMC International Medicinal} Chemistry Symposium (AIMECS 11), to be held 29 November-2 December 2011 at the Keio Plaza Hotel, Tokyo, will bring together researchers from around the world to share and discuss the most important and critical developmental challenges in medicinal chemistry. The symposium is focused on the subject "Frontier of Medicinal Science," including drug discovery chemistry, regenerative medicine, innate immunity, frontier methods for drug discovery, and other topics. The scope of medicinal chemistry has undergone noteworthy, scientifically intriguing expansion to the many fields of science. "Drug Discovery and Development" is an extremely important and challenging theme, and its solution will bring tremendous practical benefits to humanity.

A number of distinguished scientists have been invited as plenary speakers. They are Prof. E.J. Corey (Harvard University, USA), Prof. Shinya Yamanaka (Kyoto University, Japan), Prof. Shizuo Akira (Osaka
University, Japan), Prof. K.C. Nicolaou (The Scripps Research Institute and University of California, USA), Prof. Chi-Huey Wong (Academia Sinica, The Scripps Research Institute, Taiwan), and Dr. John C. Lechleiter (Eli Lilly and Company, USA). In addition, invited speakers will introduce their latest research in 21 sessions, including the ACS-Med Chem session (Diabetes/ Obesity) and the EFMC Session (Oncology).

AIMECS 11 welcomes all industrial and academic scientists to participate in this international event. The symposium also offers an excellent opportunity for young professionals and students to learn from and interact with professionals in the field. Online registration will be available beginning 1 April 2011. Participants who wish to contribute through presentation of the results of their recent research are also invited to submit an abstract for oral and/or poster presentations. The online abstract submission will be open until 31 May 2011.

See Mark Your Calendar on page 41 for contact information.

근 www.aimecs11.org

\section{Eurosoil 2012}

\section{2-6 July 2012}

Bari, Italy

\section{EUROSOIL 2012, the 4th International Congress of} the European Confederation of Soil Science Societies (ECSSS), will be held in Bari, Italy, 2-6 July 2012. The conference has been organized by the Italian Society of Soil Science (SISS) and will be presided over by Prof. Nicola Senesi of the University of Bari.

The conference will focus on and develop the various aspects of fundamental and applied soil science and technology, field approaches, and social, economic, and political implications in relation to the present and future needs and emergencies of man- kind and the environment. The conference will consist of symposia, workshops, and other events, including short courses, business meetings, open debates, roundtables, technical specialized meetings and/or demonstrations. It will be structured primarily on bottom-up proposals received from scientists, educators, and decision makers involved in soil science and related disciplines. Any interested person is cordially invited to visit the EUROSOIL 2012 website and is encouraged to submit proposal(s) for convening symposia and/or workshops and/or organizing any other kinds of events through the appropriate form available on the website.

\section{www.eurosoil2012.eu}

